\title{
Application of Wavelet Analysis for the Understanding of Vortex-Induced Vibration
}

\author{
Tomoki Ikoma, Koichi Masuda and Hisaaki Maeda \\ Department of Oceanic Architecture and Engineering, \\ College of Science and Technology (CST), Nihon University
}

Japan

\section{Introduction}

\subsection{Marine riser}

Oceans are quite important fields for us because many resources lurk there which are oil and gas under seabed, mineral resources, water heat energy and so on. Development of submarine oil has been major in the North Sea and in the Gulf of Mexico. Today, submarine oil has been developed at ultra-deep water fields of offshore of Brazil and West Africa, which does deep over $1000 \mathrm{~m}$. Deepest field developed is more than $3000 \mathrm{~m}$ in water depth of Brazilian seas. Riser system is necessary to develop and to production submarine oil. The riser is a tubing structure which is for drilling and production. Diameter of a drilling riser is greater than $50 \mathrm{~cm}$ and that of a production riser is about $20 \mathrm{~cm}$. The riser is thin rope-like tube in oceans. Therefore, the tubing behaves elastically by marine currents and ocean waves and so on.

These motion behaviors are called as Vortex-Induced Vibration (VIV). VIV of the riser is a complex phenomenon, which is dominated by the natural frequency of the riser system and behavior of vortex shedding around the rider. VIV is very important for structural design of the riser system and the platform of the drilling and the production of submarine oil and so on.

There are many studies of VIV of the riser and the drilling or the production system including the riser system in the ocean engineering field with numerical approaches, theoretical approaches and model experimental approaches. Behaviors of time variation of VIV obtained from numerical calculations or model experiments using model risers in a water tank include a complicated mechanism so it is not easy to understand them, because the time variation is not steady but transient and chaos. Therefore, we need to understand VIV phenomenon in not only time characteristics but also frequency characteristics.

For understanding frequency characteristics, we often use a power spectrum with the FFT analysis or others. However, a power spectrum does not inform us time variation of VIV characteristics. Then, the wavelet analysis can be applied to the VIV analysis because we can simultaneously understand the characteristics in time domain and frequency domain. 


\subsection{Application of wavelet analysis for study of marine riser}

The authors have investigated VIV characteristics of a circular cylinder with forced oscillation tests in still water (Ikoma \& Masuda et al., 2006, 2007). As these results, VIV behaviors have been classified to the four power spectrum pattern. However an actual orbit of the model cylinder was different even if the spectrum pattern was same. Therefore detail of VIV characteristics and behaviors cannot be understood from only a power spectrum with the FFT analysis of a time history of vibrations. In addition, a vibration phenomenon of a marine riser etc. is a non-steady problem in practice so that fluid velocity in the ocean and oscillation of an upper structure such like a production platform are an unsteady phenomenon. Therefore vibration characteristics such like VIV varies to time table.

The Hilbert transform was applied to analysis of cylinder vibration with VIV (Khalak \& Wiliamson, 1999). In there, it is described that phase deviation occurs in region entering into VIV lock-in. The Hilbert transform was useful in order to analysis of marine riser vibrations and examined frequency characteristics which vary to time table.

The wavelet transform is applied to analysis of vibration problems with VIV of a rigid circular cylinder which cross-flow vibration is allowed due to vortex shedding in this study. The wavelet analysis is possible to do the time-frequency analysis as same as the Hilbert transform analysis. Objectives of this study are: 1) to examine possibility of application of the wavelet transform to VIV analysis and 2) to discuss VIV characteristics from results of the wavelet analysis. In 2010, the wavelet analysis and the Hilbert transform were also applied to the estimation of riser behaviors (Shi et al., 2010).

This chapter introduces application of the wavelet analysis in the ocean engineering field using results of VIV characteristics. From the model experiment, relationship between the orbit pattern of vibration of the model cylinder and a contour pattern of the wavelet is considered. As a result, effectiveness of the wavelet analysis in order to understand VIV detail is given.

\section{Model experiment}

\subsection{Method of experiment}

Model experiments using a single circular cylinder or two arranged circular cylinders in tandem are carried out at a wave tank that has $27 \mathrm{~m}$ in length, $7 \mathrm{~m}$ in width and $1 \mathrm{~m}$ in water depth in the campus of Funabashi at CST of Nihon University. We cannot generate current so that forced oscillation tests in still water are carried.

An experimental method and concepts follow our own past model testing (Ikoma \& Masuda et al., 2006, 2007). In this study, a single cylinder or double cylinders in tandem arrangement to inline direction are used.

Test models of a cylinder are made of acryl resin which is rigid. However the cylinder system is not fixed because elastic vibration is allowed in only cross-flow direction by attaching a flat spring on top of the cylinder. The flat spring does not allow inline movement of the cylinder. Inline movement is due to only forced oscillation by the oscillator. VIV occurs such like rolling motion around $x$ axis which center is the flat spring. 
Number of degrees of freedom is two in sway motion and roll motion. The sway in this experiment is horizontal displacement of center of gravity in $y$ direction and rolling is rotation around $x$ axis in a coordinate system of Fig. 1. Freedom of surge corresponding to $x$ axis motion is allowed and decided due to forced oscillation by experimental operators.

\subsection{Experimental setup system}

The cylinder is suspended under a load cell through the flat spring. Most of the cylinder is submerged in still water. Side views of the experimental setup system, which corresponds to the $z-x$ plane, are illustrated in Fig. 2. The direction of forced oscillations is right and left in Fig. 2.

A load cell for measuring the total load in inline direction, which including the inertia force of a cylinder and hydrodynamic forces on a cylinder, is attached under the forced oscillation device. A Doppler current meter is installed at the straightly back of the cylinder, the current meter which moves together with the cylinder due to the forced oscillation. The current meter can measure fluid velocity of three directions in $x, y$ and $z$ axis. We measure the vertical bending moment with a flat spring on which strain gages are set.

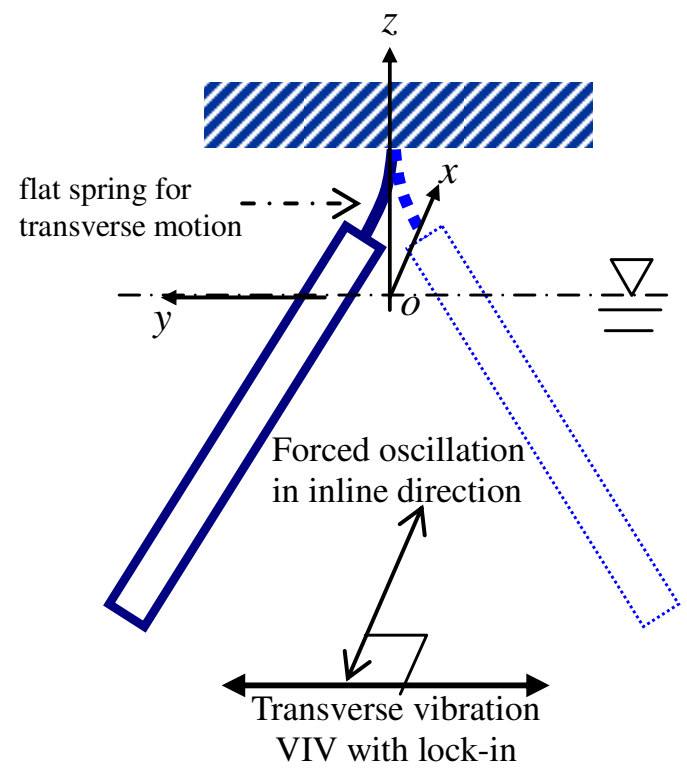

Fig. 1. Idealization of VIV in experiment

In the experiment, 1) inline displacement of forced oscillation with a potentiometer, 2) the total inline load with the load cell, 3) the bending moment with the flat spring and 4) fluid velocity at the back of the cylinder with the Doppler current meter are measured. The fluid velocity is measured at midship depth of the submerged cylinder. The VIV is evaluated by using the vertical bending moment and cross-flow displacement predicted from the bending moment. 


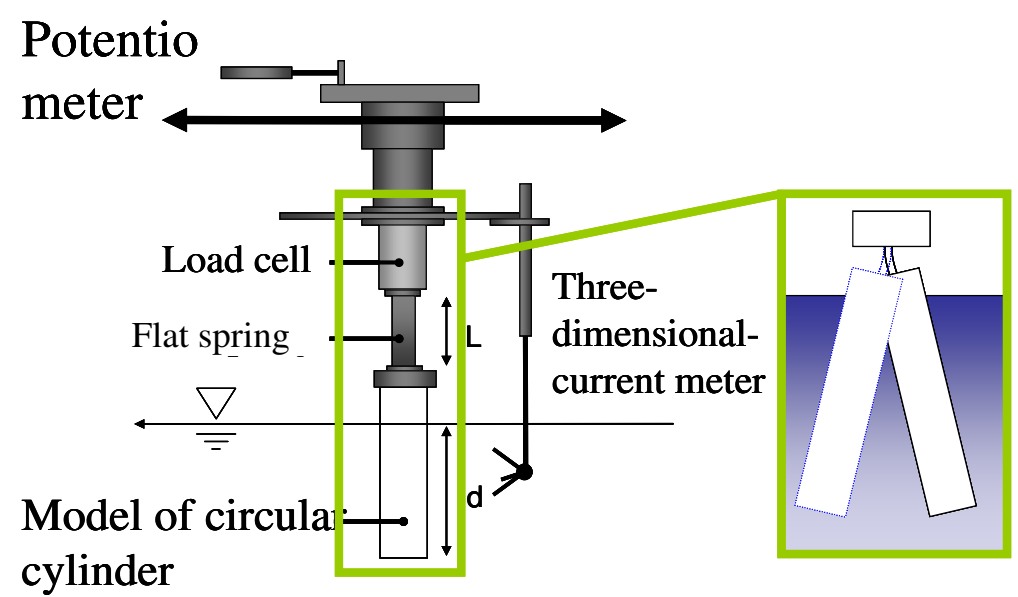

a) in case of one cylinder

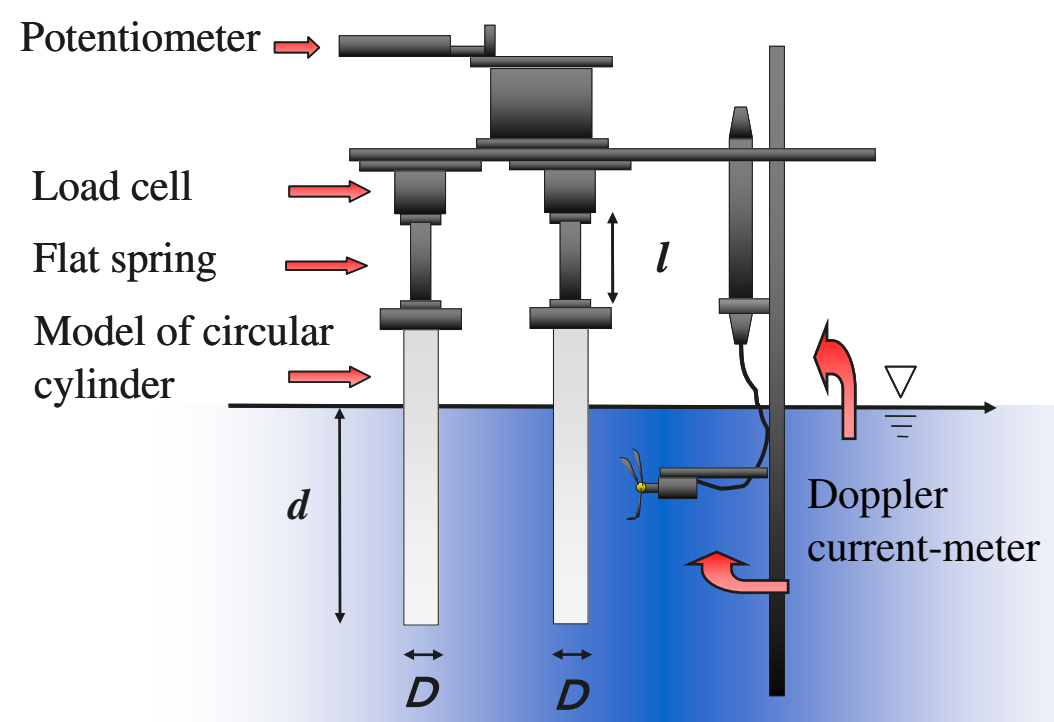

b) in case of two cylinders

Fig. 2. Side views of experimental setup system 


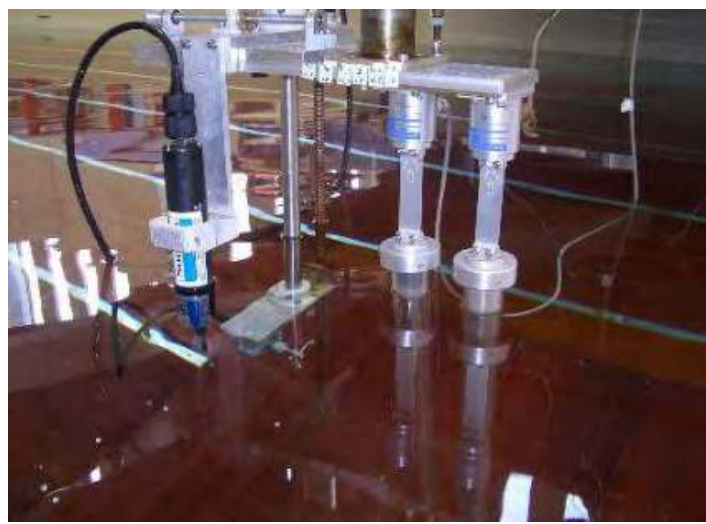

Photo 1. Side view of experimental setup system

\subsection{Experimental conditions}

Detail of the cylinder models is described in the paper (Ikoma et al., 2007). Length of the flat spring is expressed as " $l$ " in Table 1 . Natural periods $T_{n}$ of cross-flow vibration of a suspended cylinder were obtained with the plucked decay test in still water.

Water depth is set to $1.0 \mathrm{~m}$. The amplitude of forced oscillation is $7.2 \mathrm{~cm}$, the KeuleganCarpenter $\left(K_{C}\right)$ number accordingly corresponds to 5.7 and 9.0 in the experiments.

In case of double cylinders, the cylinders are straightly suspended, and then the distance $l_{d}$ between the center to center of both the cylinders is varied such as Table 2. The distance ratio $s$ is defined as follows,

$$
s=\frac{l_{d}}{D}
$$

The front cylinder and the back cylinder are defined as Fig. 3.

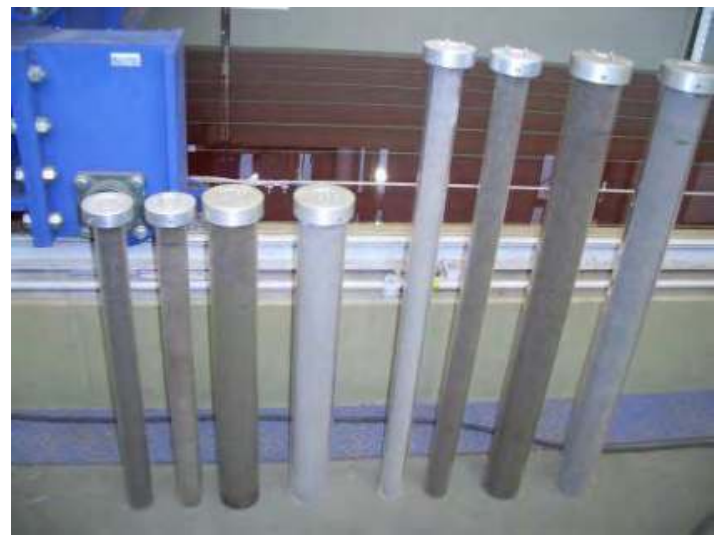

Photo 2. Experimental models filled with sand 


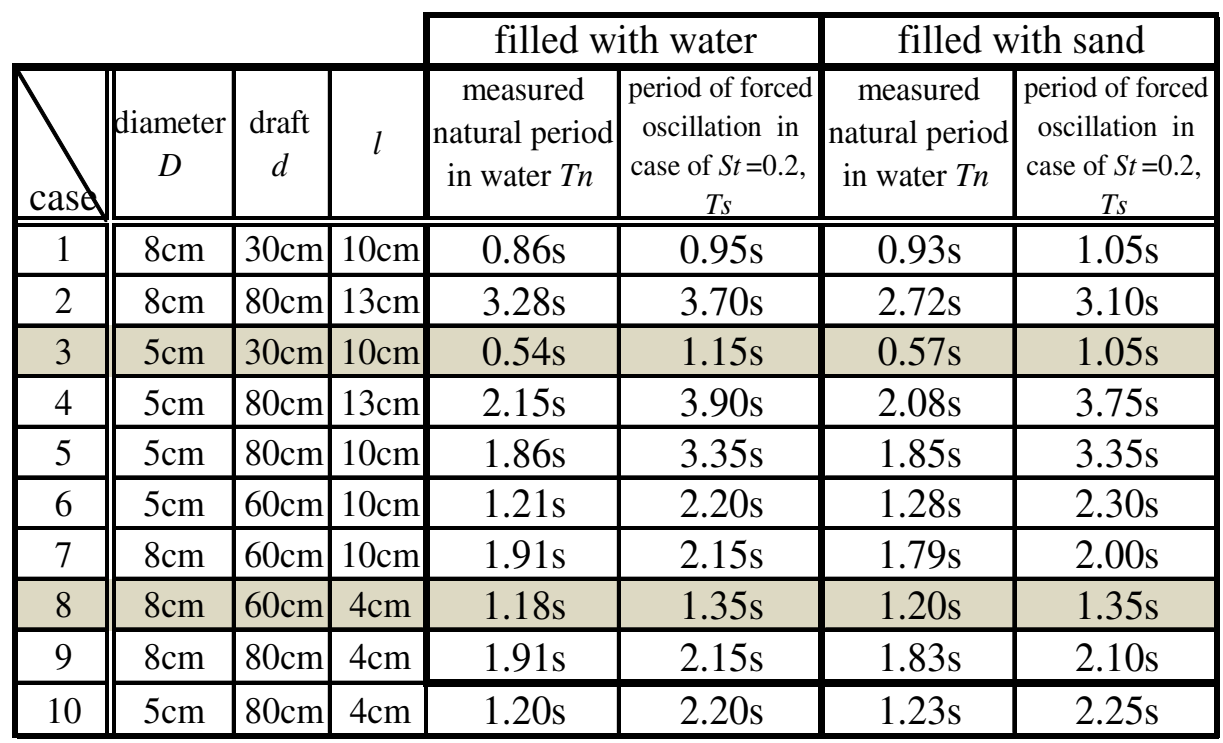

a) for single cylinder

\begin{tabular}{|c||c|c|c|c|c|}
\hline moded & $\begin{array}{c}\text { diameter } \\
D\end{array}$ & $\begin{array}{c}\text { draft } \\
d\end{array}$ & $l$ & $\begin{array}{c}\text { measured natural } \\
\text { period in water } \\
T n\end{array}$ & $\begin{array}{c}\text { period of forced } \\
\text { oscillation in case } \\
\text { of } S t=0.2, T s\end{array}$ \\
\hline \hline 1 & $5 \mathrm{~cm}$ & $60 \mathrm{~cm}$ & $10 \mathrm{~cm}$ & $1.28 \mathrm{~s}$ & $2.00 \mathrm{~s}$ \\
\hline 2 & $5 \mathrm{~cm}$ & $80 \mathrm{~cm}$ & $10 \mathrm{~cm}$ & $1.85 \mathrm{~s}$ & $3.35 \mathrm{~s}$ \\
\hline 3 & $8 \mathrm{~cm}$ & $60 \mathrm{~cm}$ & $10 \mathrm{~cm}$ & $1.79 \mathrm{~s}$ & $2.00 \mathrm{~s}$ \\
\hline 4 & $8 \mathrm{~cm}$ & $80 \mathrm{~cm}$ & $10 \mathrm{~cm}$ & $2.52 \mathrm{~s}$ & $2.85 \mathrm{~s}$ \\
\hline
\end{tabular}

b) for double cylinders

Table 1. Principal particulars of cylinder model setting

\begin{tabular}{|c|c|c|c|c|c||c|c|}
\hline$D$ & \multicolumn{5}{|c||}{$5 \mathrm{~cm}$} & \multicolumn{2}{c|}{$8 \mathrm{~cm}$} \\
\hline \hline$l_{d} \mathrm{~cm}$ & 10 & 13 & 15 & 18 & 20 & 16 & 20 \\
\hline $\mathrm{S}$ & 2.0 & 2.5 & 3.0 & 3.5 & 4.0 & 2.0 & 2.5 \\
\hline
\end{tabular}

Table 2. Variation of distance ratio of straight cylinders 


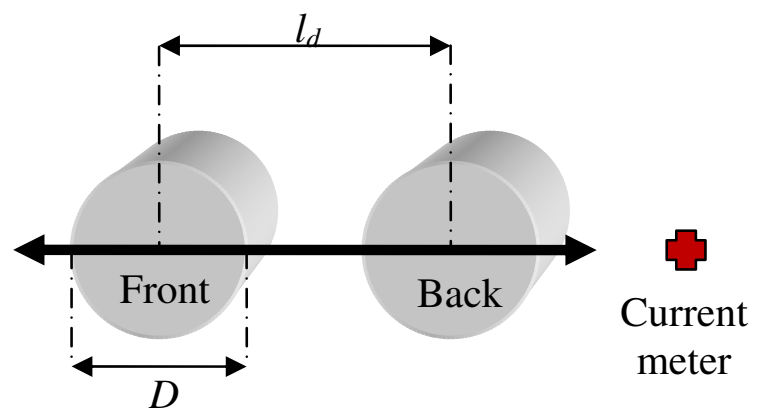

Fig. 3. Distance ratio between two cylinders

\subsection{Definitions of nominal period and nominal frequency}

The K-C number and the period of $T_{s}$ are defined as same as them (Ikoma et al., 2007) as follows,

$$
K_{C}=\frac{U_{O} T}{D}
$$

where $U_{O}$ is the maximum velocity of forced oscillation, $T$ stands for the period of the forced oscillation. The forced oscillation is simple harmonic motion in this study, hence eqn. (2) can be rewritten as follows,

$$
K_{C}=2 \pi \frac{a}{D}
$$

in which $a$ is amplitude of the forced oscillation in inline direction.

The range of periods of the forced oscillation is from about 0.4 seconds to 4.6 seconds, the Reynolds $\left(R_{e}\right)$ numbers accordingly correspond to about $5.0 \mathrm{e}+3$ to $6.0 \mathrm{e}+5$ if the maximum velocity $U_{O}$ of the forced oscillations are applied to the calculation.

The natural frequency of transverse vibration varies due to the length of a flat spring. The experimental conditions of each case are shown in Table 1. ' $S_{t}^{\prime}$ in Table 1 is the Strouhal number and is defined in this study as follows,

$$
S_{t}=\frac{f_{s} D}{U_{O}},
$$

in which $f_{s}$ is the frequency of vortex shedding. The Strouhal number has been well known as about 0.2 in range of $R_{e}>1.0 \mathrm{e}+3$. In this paper, the Strouhal number is approximately fixed to, 


$$
S_{t} \approx 0.2 \text {. }
$$

' $T_{s}^{\prime}$ in Table 1 corresponds to the period of the forced oscillation which corresponds to about 5.0 in the nominal reduced velocity. The lock-in phenomenon of VIV is therefore expected in each experimental case when the model is in forced inline oscillations with the period of $T_{s}$. ' $T_{s}^{\prime}$ is calculated with following equations,

$$
\begin{gathered}
\frac{f_{s} D}{U_{O}}=0.2, \\
f_{s}=0.2 \frac{U_{O}}{D}, \\
T_{s}=\frac{1}{f_{s}} .
\end{gathered}
$$

Therefore, the frequency of vortex shedding $f_{s}$ is not an actual frequency, but is a nominal frequency in this study.

\section{Wavelet analysis}

The wavelet analysis is the time-frequency analysis for time histories such like the Hilbert transform. The wavelet transform is defined as follows,

$$
W_{T}(b, a)=\frac{1}{\sqrt{|a|}} \int_{-\infty}^{\infty} f(t) \cdot \psi\left(\frac{t-b}{a}\right) d t,
$$

where $f(t)$ is a time history, $a$ stands for a dilation parameter and $b$ stands for a location parameter. " $\psi(t)$ " is the mother wavelet function. The Gabor's mother wavelet is applied such as follows in this study,

$$
\psi(t)=\frac{1}{\sqrt{2 \pi \sigma^{2}}} \exp \left[-\frac{t^{2}}{2 \sigma^{2}}\right] \cdot e^{i \omega_{0} t},
$$

where $\sigma$ is a damping parameter of the mother wavelet function and $\omega_{0}$ is a principle angular frequency. Half of the natural angular frequency of each model is applied in this study.

When the damping parameter $\sigma$ becomes smaller, the mother function be attenuated soon. And then, resolution of frequency is high although resolution of time gets worse. It is a merit to select the Gabor's wavelet because the dilation parameter $a$, which corresponds to a scaling parameter, is individual to the resolution parameter $\sigma$. The parameters are consequently individual each other so that the tuning of the parameters in order to draw the wavelet contour is not difficult.

In this study, $b$ is set at 0.4 seconds, $a$ is carried out from 0.0 to 3.0 with resolution of 0.2 and $\sigma$ is 1.0. 
A sampling frequency of the experimental recording has been $500 \mathrm{~Hz}$, which corresponds to 2.0e-3 seconds in the sampling time. '0.4 seconds' of $b$ in the time sifting for the wavelet analysis corresponds to 200 sampling data skipping. In addition, the shortest natural period of cross-flow vibration in the experimental models in Tables $1 \mathrm{a}$ ) and $1 \mathrm{~b}$ ) is 0.86 seconds. If the bi-harmonic vibration in VIV in this case occurs, the vibration period is 0.43 seconds. The resolution would be thereby enough 0.4 seconds. Using $b=0.4$, variation pattern of the wavelet would be able to be reproduced. The step of $a$ is now 0.2 . The parameter $a$ corresponds to a resolution of the frequency component. The cross-flow vibration appears relatively simply from the FFT analysis so that the resolution of 0.2 may be reasonable.

\section{Orbit patterns and power spectrum patterns}

In case of a single cylinder experiment (Ikoma \& Masuda et al., 2006, 2007), the four patterns of the power spectrum of VIV have been found such like Fig. 4. In addition, there was an adequate correlation between the orbit pattern and the spectrum pattern in the paper (Ikoma et al., 2007). However both the power spectrum patterns of the orbit patterns of the type $U$ and the type 8 correspond to the pattern 4 which is bi-harmonic type. Therefore detail of VIV behavior cannot be understood from a result with the FFT analysis of VIV.

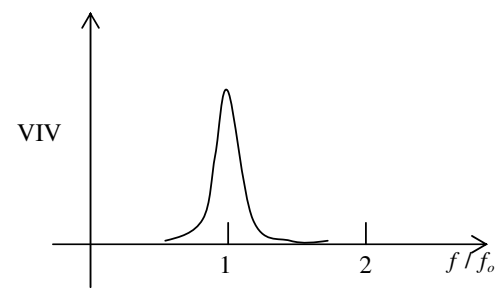

a) Pattern 1 (general type)

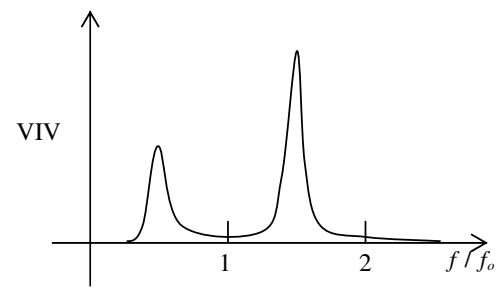

c) Pattren 3 (two peaks type)

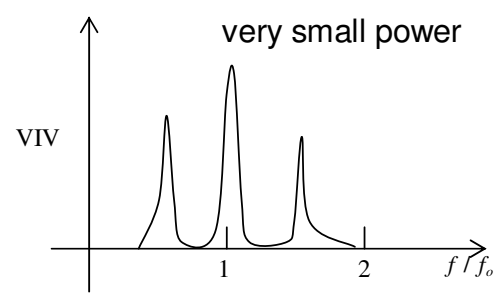

b) Pattern 2 (three peaks type)

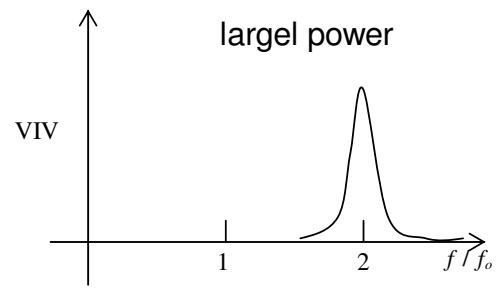

d) Pattern 4 (bi-harmonic type)

Fig. 4. Classifications of power spectrum patterns of VIV [1]

\section{Results and discussion}

\subsection{Orbit patterns}

From the experiment using the single cylinder, orbit patterns can be classified to six patterns such as Fig. 5. The net type is specified to N1 and N2. It can be considered that response of the type $U$ and the type 8 corresponds to VIV lock-in. 


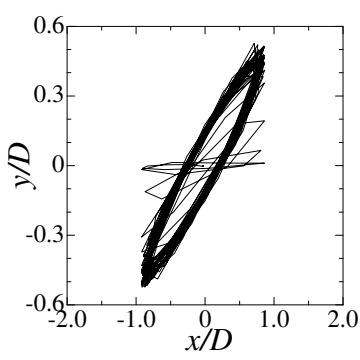

Type $O$

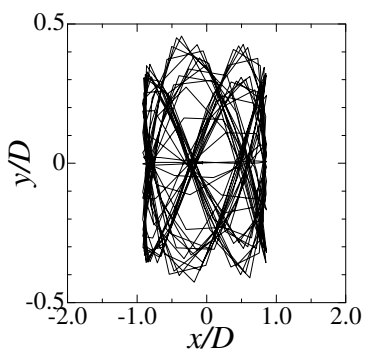

Type $N 2$

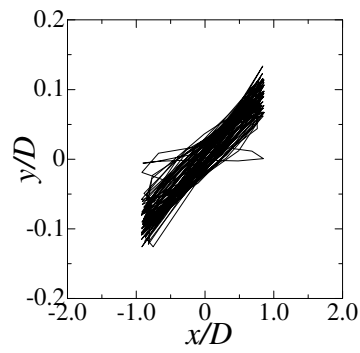

Ordinary Type

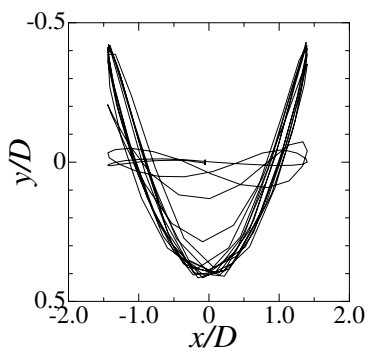

Type $U$

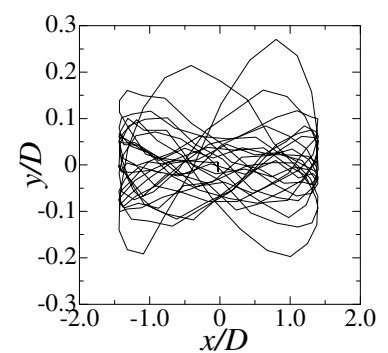

Type $N 1$

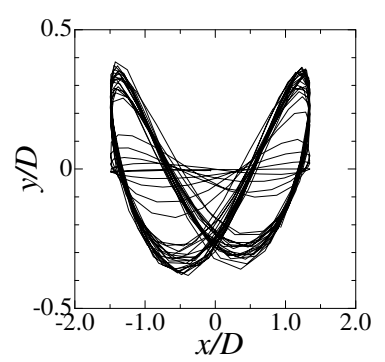

Type 8

Fig. 5. Classifications of orbit patterns of VIV

\subsection{Wavelet characteristics of single cylinder}

In case of a single cylinder, wavelet patterns are made a general classification to five. These patterns are not decided due to experimental cases such as Table 1-a). Results of wavelet analysis in case of the case 8 show in Figs. 6, where "T" in subtitles stands for period of the forced oscillation. A vertical axis is the dilation parameter $a$ and horizontal axis is time of VIV response. These results are the vertical bending moment which corresponds to crossflow vibration.

In Figs. 6, a) corresponds to the orbit pattern of Type $O$. In Wavelet contours from a) to c), response frequency is confirmed in wide band of $a$ which is vertical axis. In case of Type $U$, there is no striped pattern from 0.0 to 1.0 in $a$.

Such this tendency can be also confirmed in case of Type 8 . In the case 8 , Type 8 doesn't occur so that a wavelet pattern corresponding to Type 8 is explained by using the case 3 .

From Figs. 6-e) and 7-b) which results correspond to Type $U$, in range from 2.0 to 3.0 in $a$, we can confirm a clear striped pattern. However, the striped pattern is broken around $a=1.0$ when the orbit gets Type 8 . 


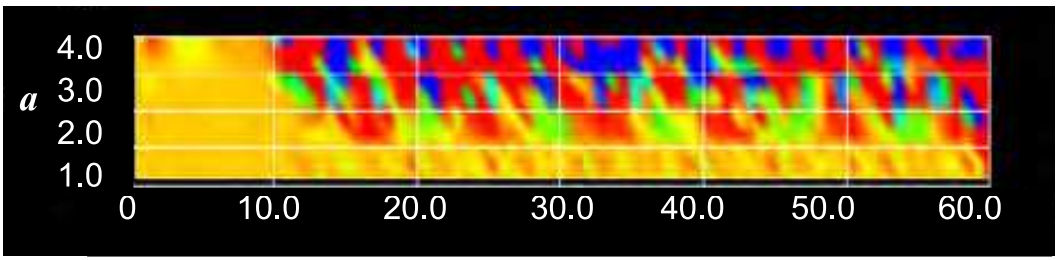

a) $\mathrm{T}=1.15 \mathrm{~s}$, orbit corresponding to Type $O$

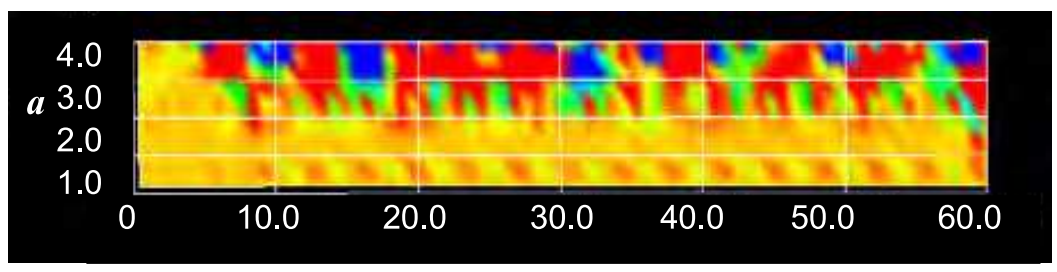

b) $\mathrm{T}=1.25 \mathrm{~s}$, orbit corresponding to Ordinary Type

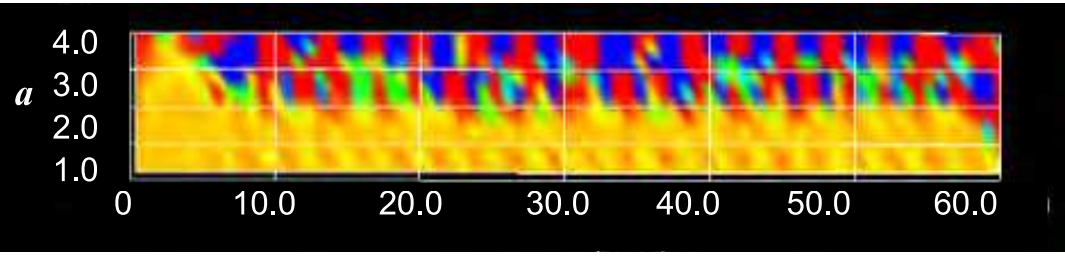

c) T=1.55 s, orbit corresponding to Type Net 1

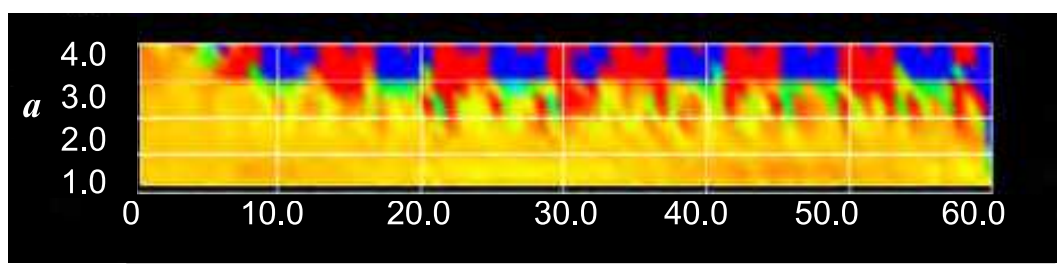

d) $\mathrm{T}=2.00 \mathrm{~s}$, orbit corresponding to Type Net 2

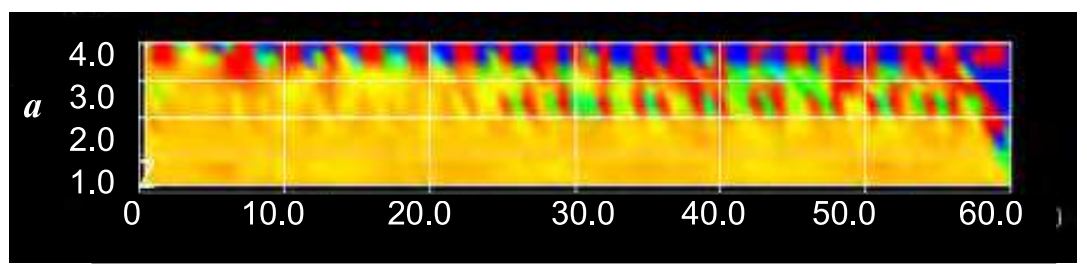

e) $\mathrm{T}=2.30 \mathrm{~s}$, orbit corresponding to Type $U$

Fig. 6. Patterns of wavelet analysis of Case 8 


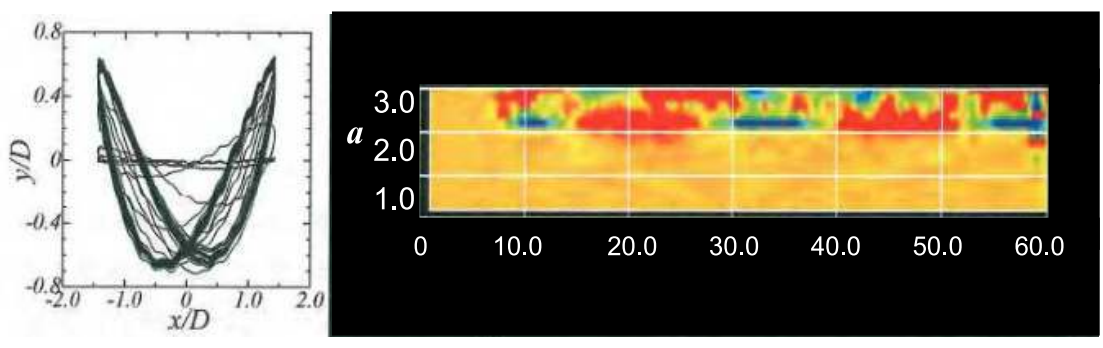

a) T=1.00 s, orbit corresponding to Type 8

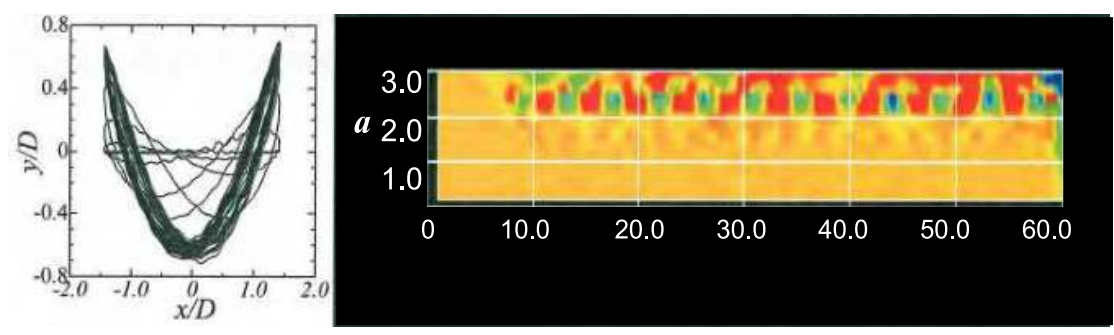

b) $\mathrm{T}=1.05 \mathrm{~s}$, orbit corresponding to Type $U$

Fig. 7. Patterns of wavelet analysis of Case 3

\subsection{Wavelet characteristics of double cylinders in tandem}

Results of the vertical bending moment corresponding to VIV with the wavelet analysis are discussed using the results in case of the model 1 in Table 1-b). Correspondence between the orbit and the wavelet pattern was similar to cases of the single cylinder. When the distance ratio increased, VIV behavior resembled the single cases. Therefore the results in case of the distance ratio $s=2.0$ are described here.

Figures 8 to 13 show results of the wavelet analysis, the orbit and a power spectrum of the vertical bending moment. Representations of "front" and "back" in the figures mean follows. The cylinder set on a side of starting direction of the forced oscillation corresponds "front" such as Fig. 3. " $f$ " is a frequency $\mathrm{Hz}$ and " $f_{0}$ " is also a frequency $\mathrm{Hz}$ of the forced oscillation on the horizontal axis of the power spectra.

In Figs. 8, the behavior of vibration of both the cylinder is quite different. VIV is not induced strongly. VIV lock-in is confirmed in Figs. 9 to 12. However the behavior of the vibration is different each case from the orbit, even then a shape of the power spectrum of Figs. 9 to 12 are same very much. VIV occurs as bi-harmonic vibration to the frequency of the forced oscillation. The third harmonic vibration can be found on the power spectrum in Figs. 12-a). When the character of " 8 " is broken and becomes flat, a response component which is higher than the bi-harmonic frequency emerges. 


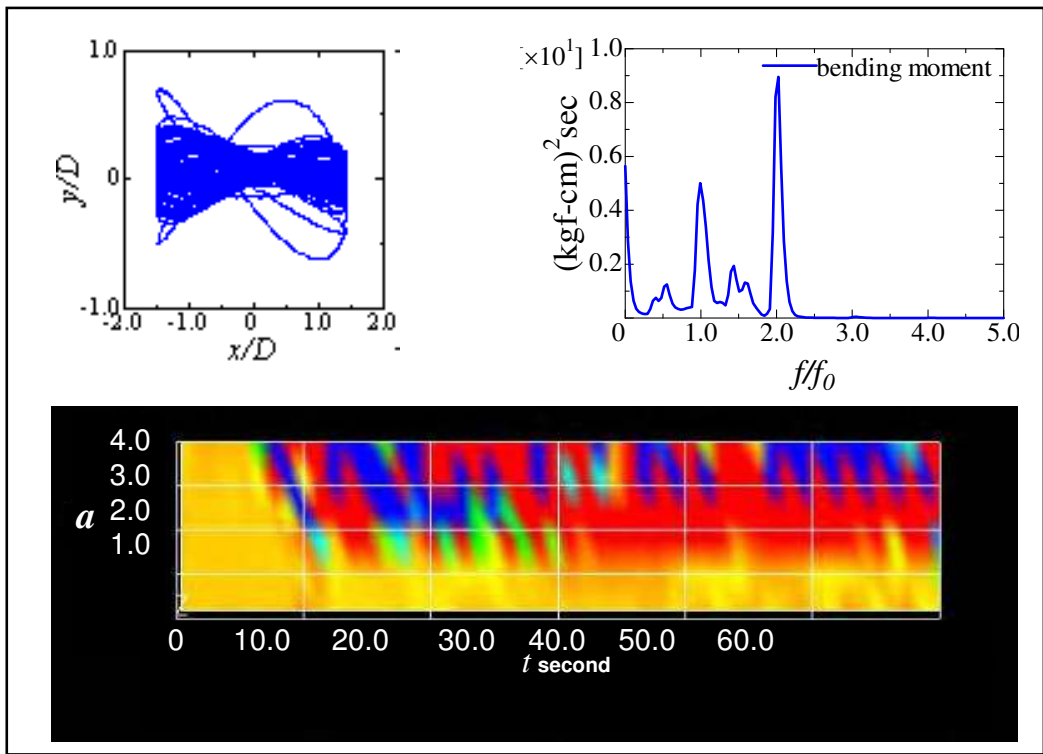

a) on front cylinder

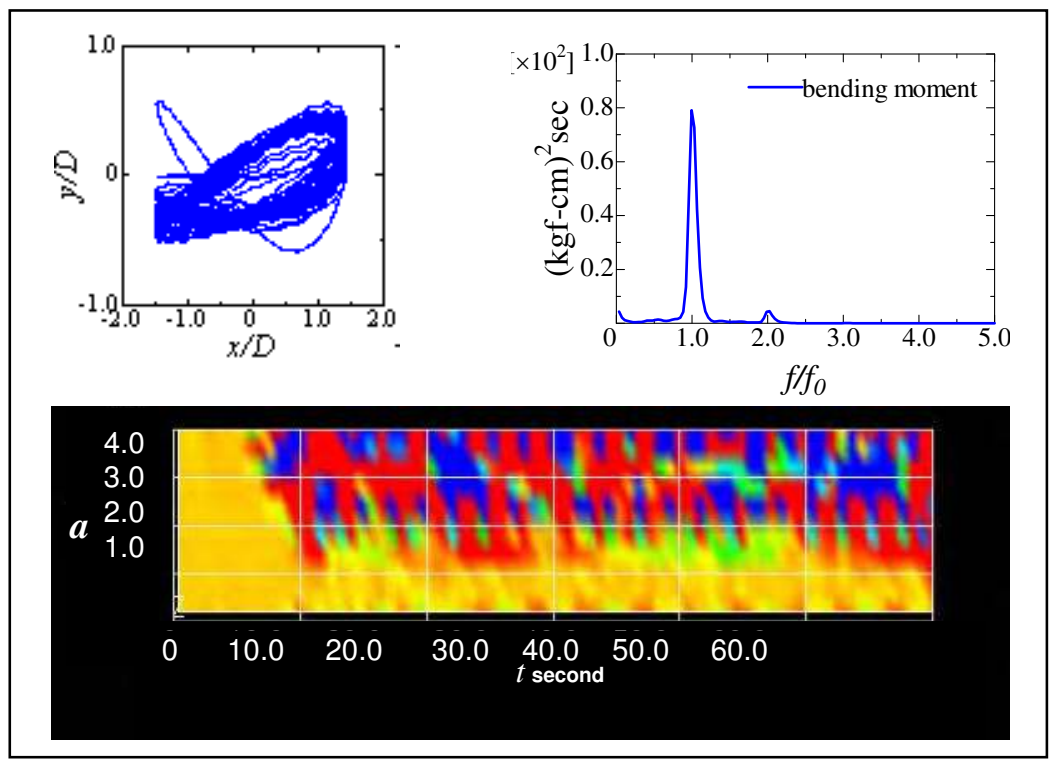

b) on back cylinder

Fig. 8. Comparisons of orbit, power spectrum and wavelet pattern of vertical bending moment in case of $s=2$ and $\mathrm{T}=1.2 \mathrm{~s}$ 

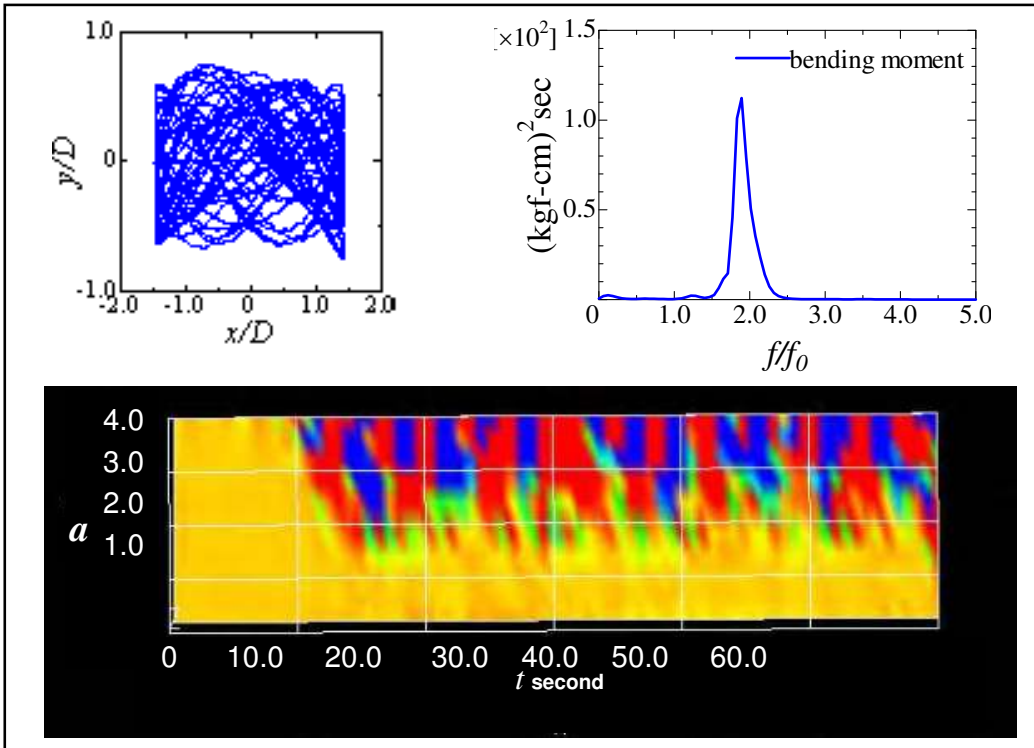

a) on front cylinder

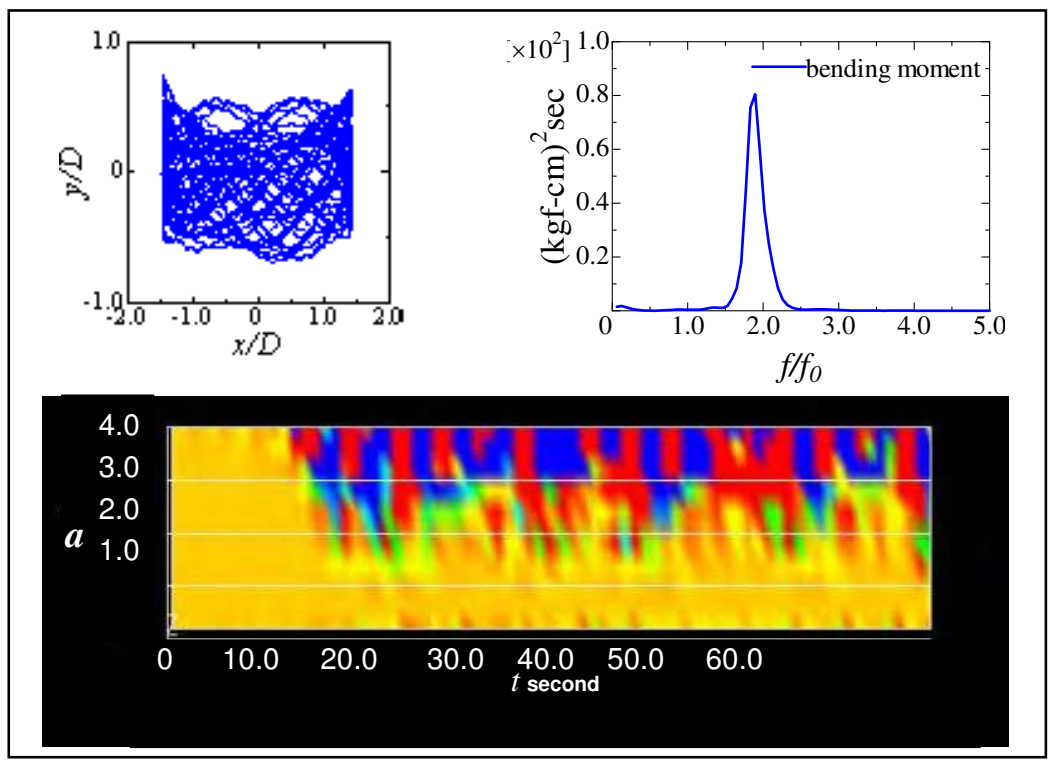

b) on back cylinder

Fig. 9. Comparisons of orbit, power spectrum and wavelet pattern of vertical bending moment in case of $s=2$ and $\mathrm{T}=2.0 \mathrm{~s}$ 

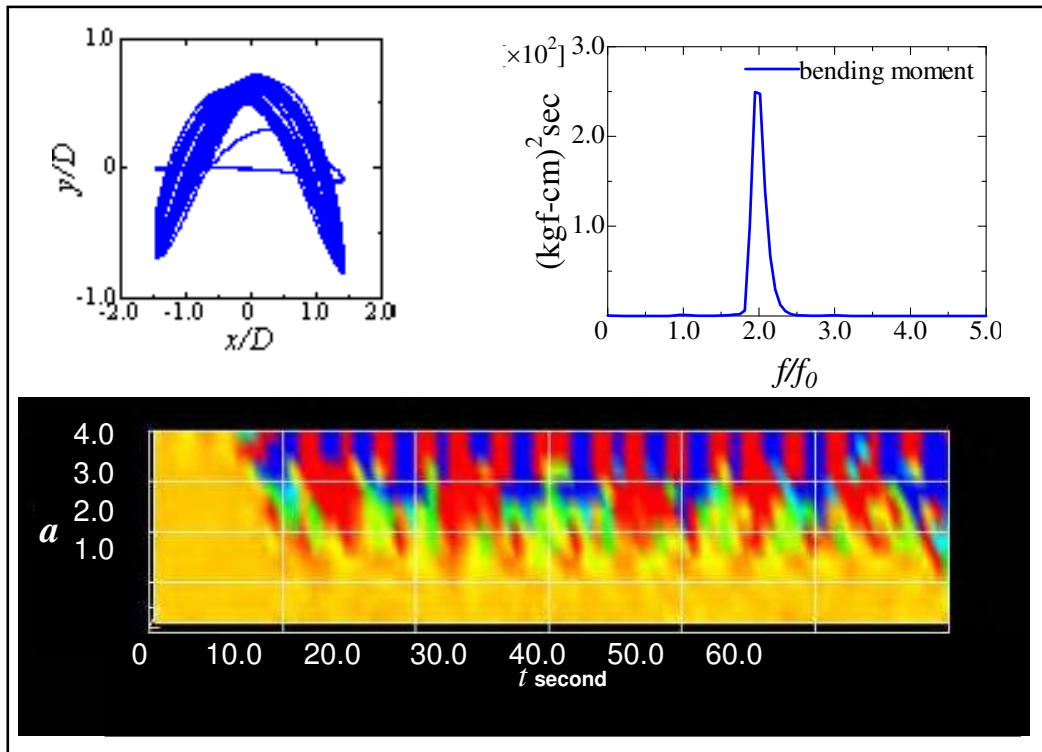

a) on front cylinder

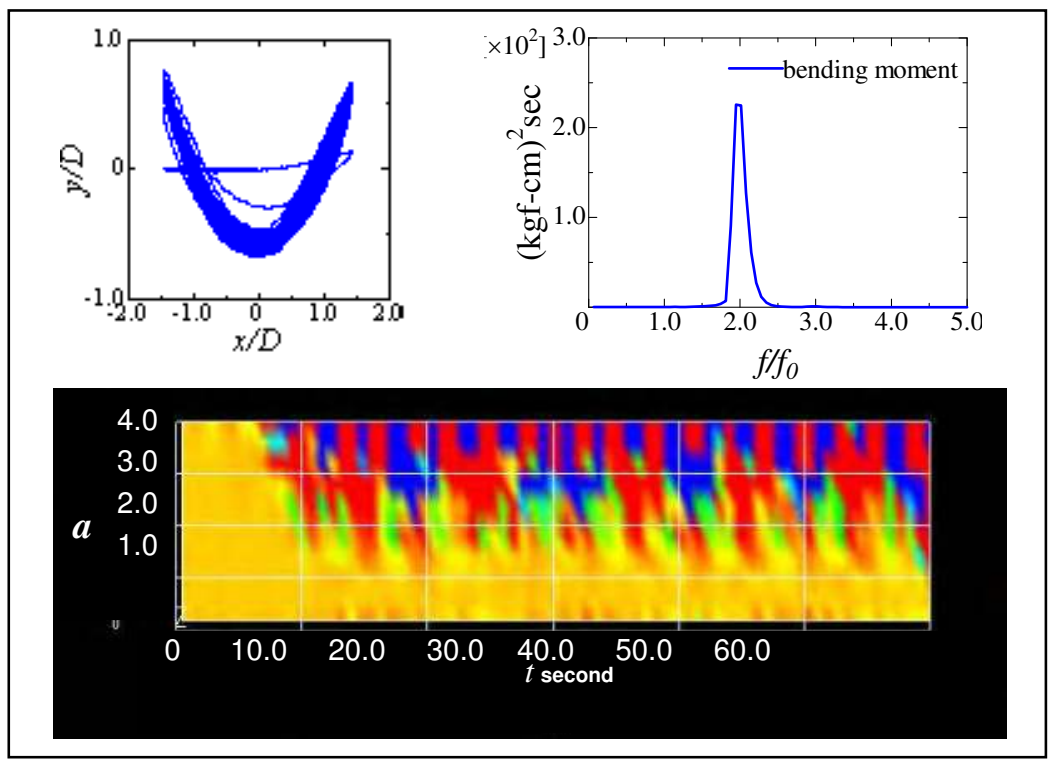

b) on back cylinder

Fig. 10. Comparisons of orbit, power spectrum and wavelet pattern of vertical bending moment in case of $s=2$ and $\mathrm{T}=2.2 \mathrm{~s}$ 

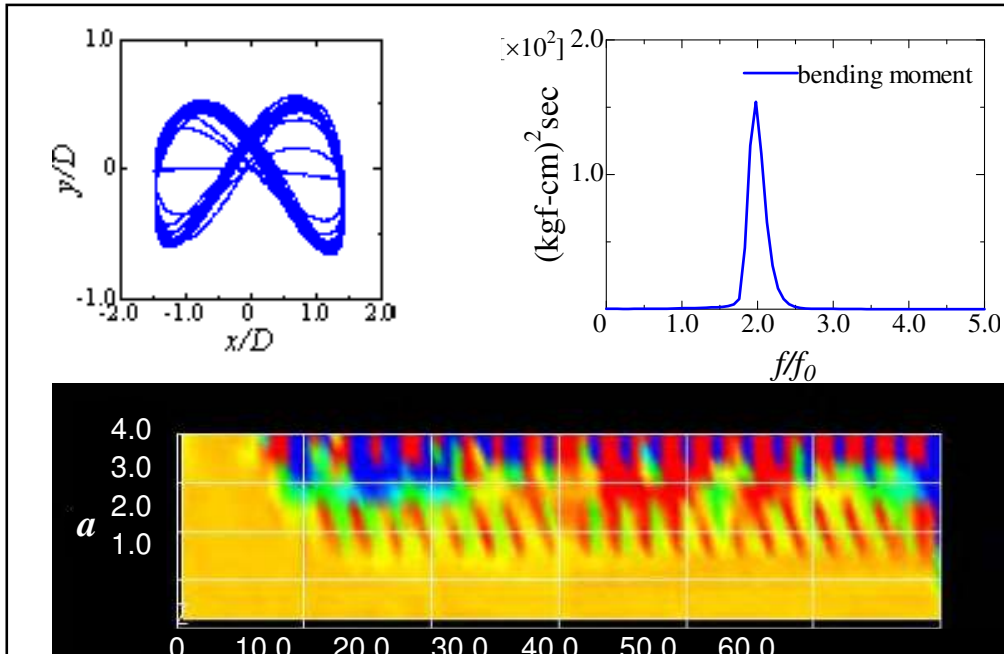

$t$ second

a) on front cylinder

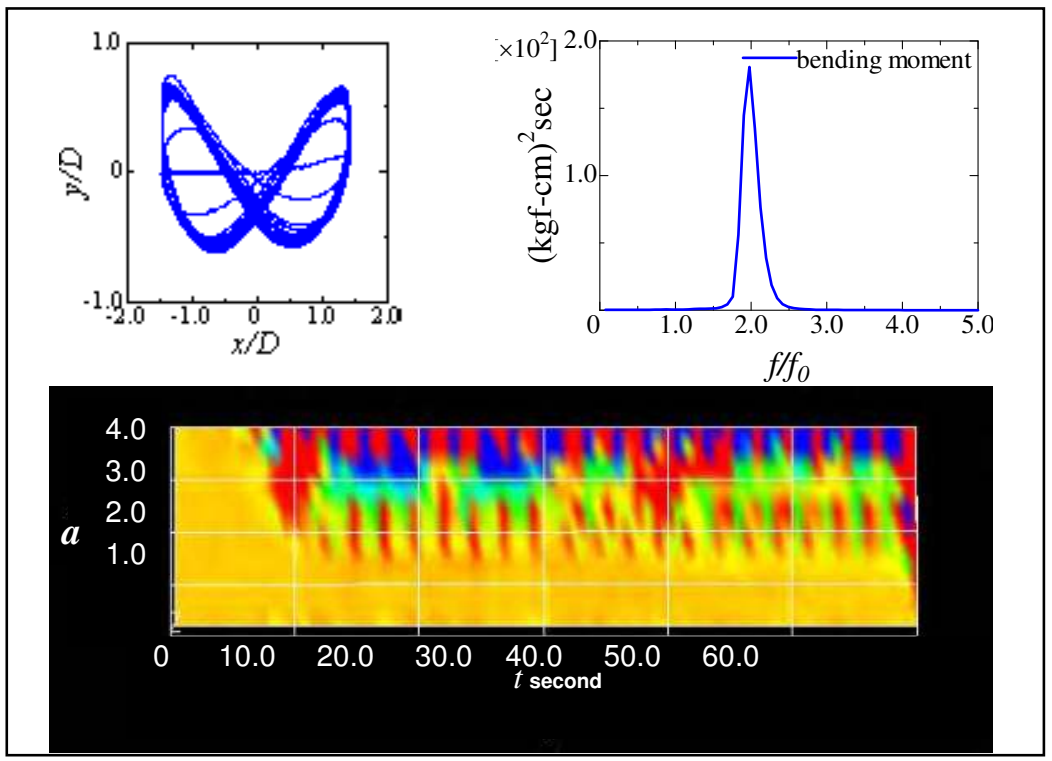

b) on back cylinder

Fig. 11. Comparisons of orbit, power spectrum and wavelet pattern of vertical bending moment in case of $s=2$ and $\mathrm{T}=2.4 \mathrm{~s}$ 

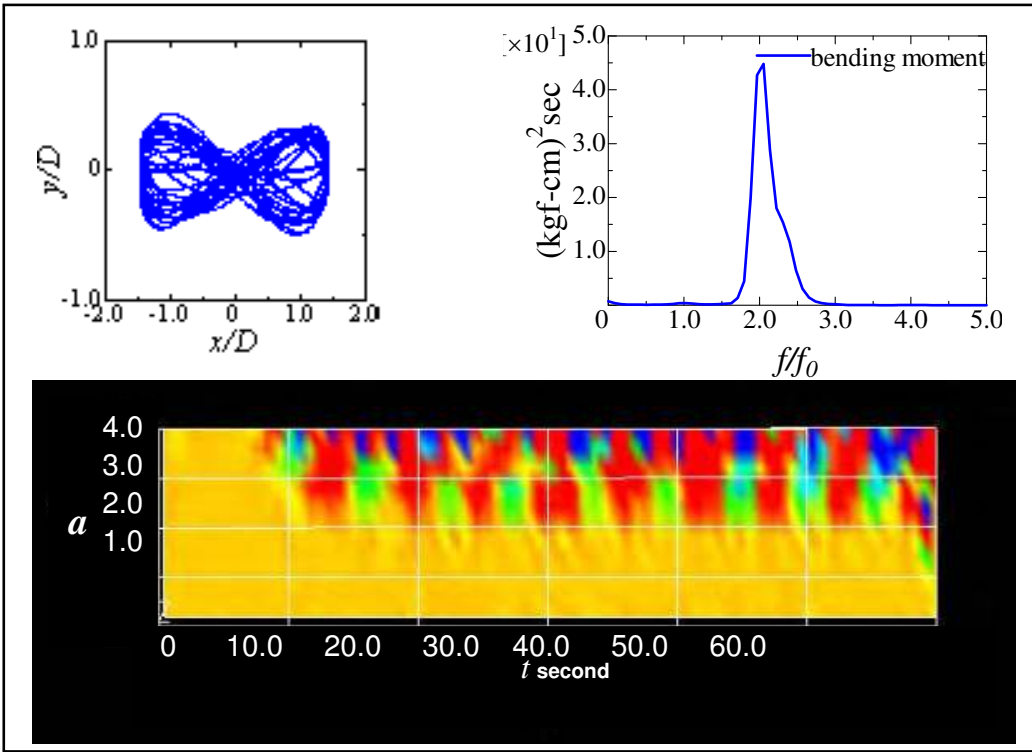

a) on front cylinder

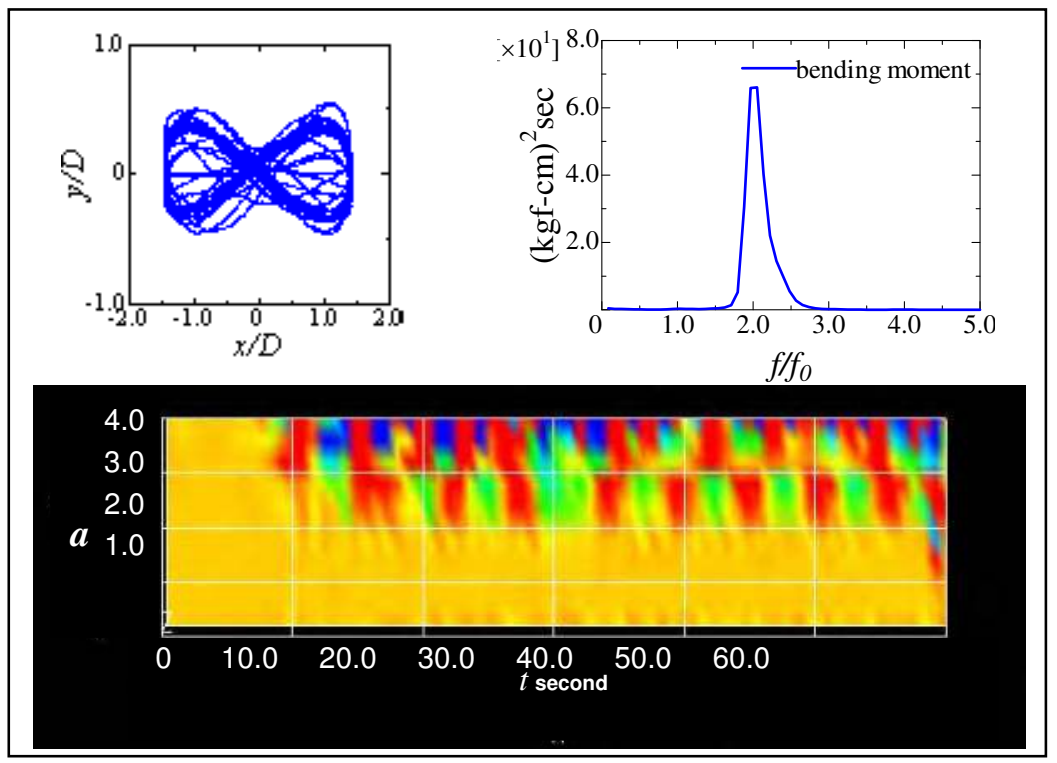

b) on back cylinder

Fig. 12. Comparisons of orbit, power spectrum and wavelet pattern of vertical bending moment in case of $s=2$ and $\mathrm{T}=2.8 \mathrm{~s}$ 

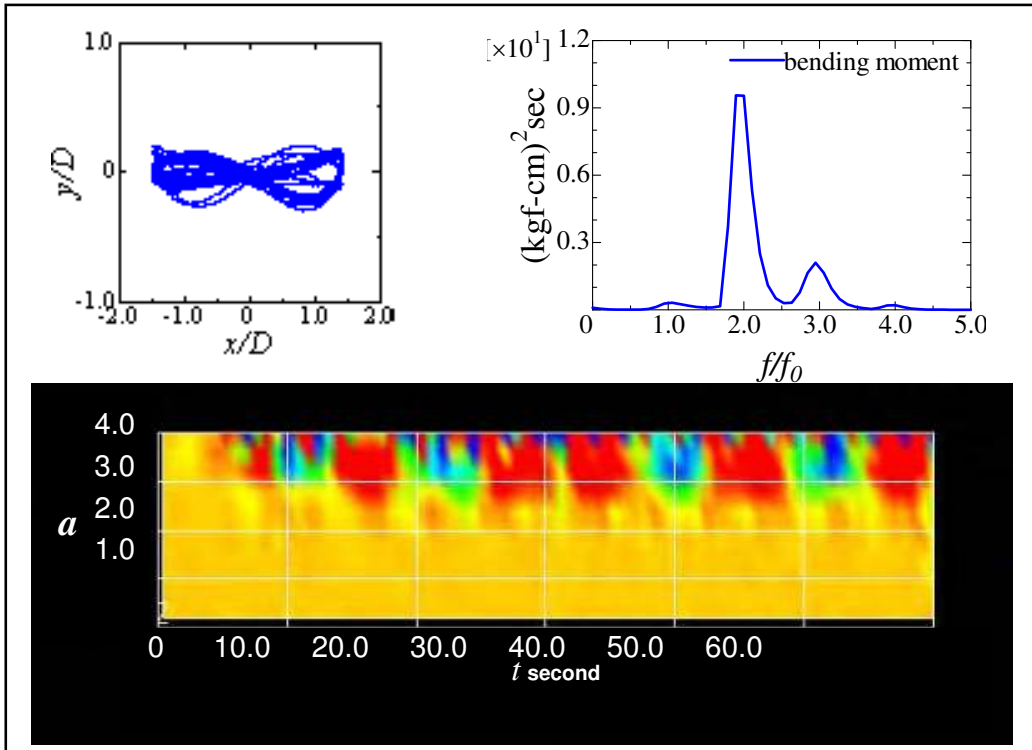

a) on front cylinder

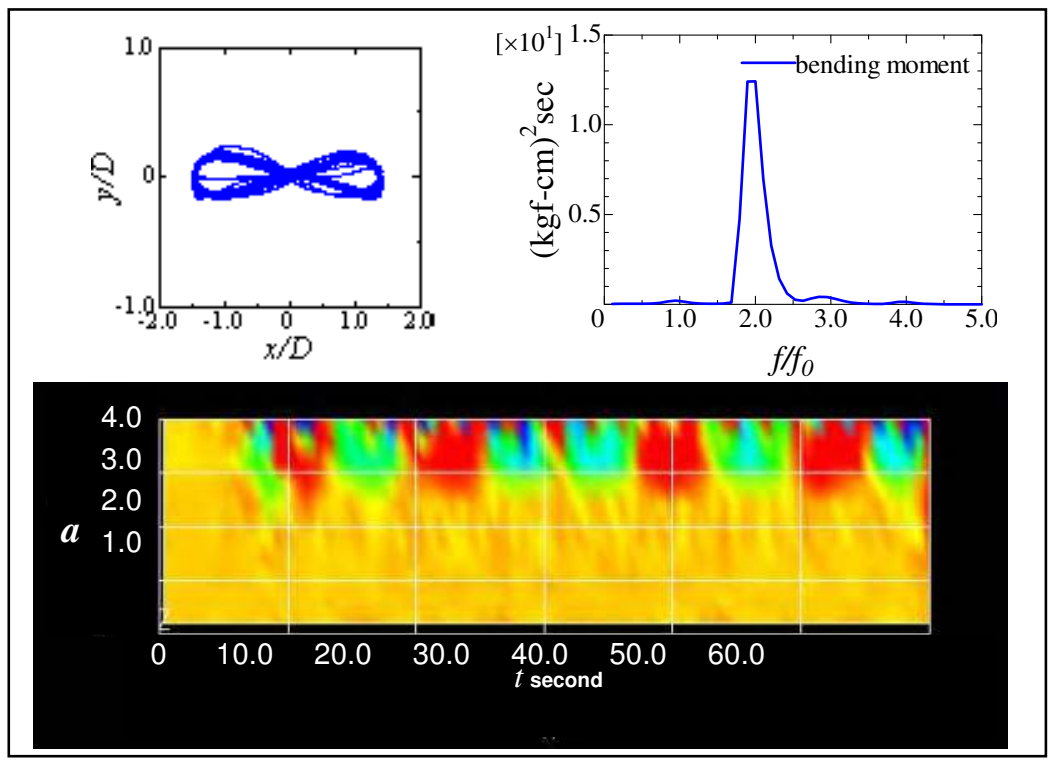

b) on back cylinder

Fig. 13. Comparisons of orbit, power spectrum and wavelet pattern of vertical bending moment in case of $s=2$ and $\mathrm{T}=3.45 \mathrm{~s}$ 
Above discussions can be explained from results of the orbits and the power spectra. However all of the wavelet patterns, comparing with results of each period of the forced oscillation, are clearly different. In particular, difference of the VIV behavior cannot be understood from only the power spectra drawing the bi-harmonic vibration such as Figs. 12 to 15 . We can found the unique striped pattern on the wavelet contours. At first we notice that the striped pattern gets blurred when the orbit is more complex. When the stripe becomes clearer, in range from 1.5 to 2.5 in $a$, the orbit varies from the Net type to the 8 type through the $U$ type. From the wavelet pattern, we can know vibration behavior of the cylinder including cross-flow and in-line vibration. In Figs. 16, it can seem that not only the third order but also the fourth order vibration component appear. At around 2.5 in $a$, the wavelet stripes of Fig. 16 get blurrier than that of Fig. 15. From these, it can be considered that a result with the wavelet analysis is higher resolution or more sensitive than that with the FFT analysis to frequency components. Therefore detail of vibration behaviors of cylindrical structures with VIV can be investigated by using the wavelet transform analysis.

\section{Conclusion}

In this paper, the wavelet transform was applied to the analysis of time histories of vibration of circular cylinders with the vortex induced vibration. From the results, the summary is as follows:

- The orbit pattern of the cylinder roughly corresponds to the unique pattern of the wavelet contour. Therefore the vibration behavior can be known from time history data of arbitral vibration with the wavelet analysis. However calibration is necessary.

- Results with the wavelet analysis are more sensitive than that with the FFT analysis to frequency resolution.

- When VIV lock-in occurs, the pattern of the wavelet contour becomes to clear stripes.

- The Gabor's mother wavelet function is useful for analysis of VIV. In addition, the wavelet transform analysis is effective in order to investigate VIV detail.

\section{References}

Ikoma, T.; Masuda, K.; Maeda, H. \& Hanazawa, S. (2007) Behaviors of Drag and Inertia Coefficients of Circular Cylinders under Vortex-induced Vibrations with Forced Oscillation Tests in Still Water, Proceedings of OMAE'07, CD-ROM OMAE2007-29473, ASME

Khalak, A. \& Williamson C.H.K. (1999) Motions, Forces and Mode Transitions in Vortex-induced vibration at low mass-damping, Journal of Fluids and Structures, Vol.13, pp.813-851

Masuda, K.; Ikoma, T.; Kondo, N. \& Maeda, H. (2006) Forced Oscillation Experiments for VIV of Circular Cylinders and Behaviors of VIV and Lock-in Phenomenon, Proceedings of OMAE'06, CD-ROM OMAE2006-92073, ASME

Shi, C.; Manuel, L.; Tognarelli, M.A. \& Botros, T. (2010) On the Vortex-Induced Vibration Response of a Model Riser and Lacatin of Sensors for Fatigue Damage Prediction, Proceedings of OMAE'10, CD-ROM OMAE2010-20991, ASME 
Williamson, C.H.K. \& Roshko, A. (1988) Vortex formation in the wake of an oscillating cylinder, Journal of Fluids and Structures 2, pp.355-381 


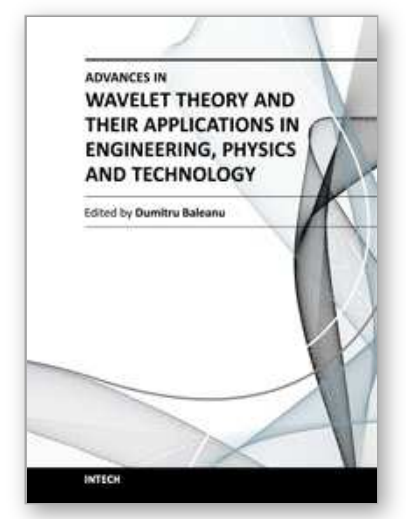

\author{
Advances in Wavelet Theory and Their Applications in \\ Engineering, Physics and Technology \\ Edited by Dr. Dumitru Baleanu
}

ISBN 978-953-51-0494-0

Hard cover, 634 pages

Publisher InTech

Published online 04, April, 2012

Published in print edition April, 2012

The use of the wavelet transform to analyze the behaviour of the complex systems from various fields started to be widely recognized and applied successfully during the last few decades. In this book some advances in wavelet theory and their applications in engineering, physics and technology are presented. The applications were carefully selected and grouped in five main sections - Signal Processing, Electrical Systems, Fault Diagnosis and Monitoring, Image Processing and Applications in Engineering. One of the key features of this book is that the wavelet concepts have been described from a point of view that is familiar to researchers from various branches of science and engineering. The content of the book is accessible to a large number of readers.

\title{
How to reference
}

In order to correctly reference this scholarly work, feel free to copy and paste the following:

Tomoki Ikoma, Koichi Masuda and Hisaaki Maeda (2012). Application of Wavelet Analysis for the Understanding of Vortex-Induced Vibration, Advances in Wavelet Theory and Their Applications in Engineering, Physics and Technology, Dr. Dumitru Baleanu (Ed.), ISBN: 978-953-51-0494-0, InTech, Available from: http://www.intechopen.com/books/advances-in-wavelet-theory-and-their-applications-in-engineeringphysics-and-technology/application-of-wavelet-analysis-for-the-understanding-of-vortex-induced-vibration-

\section{INTECH}

open science | open minds

\author{
InTech Europe \\ University Campus STeP Ri \\ Slavka Krautzeka 83/A \\ 51000 Rijeka, Croatia \\ Phone: +385 (51) 770447 \\ Fax: +385 (51) 686166 \\ www.intechopen.com
}

\author{
InTech China \\ Unit 405, Office Block, Hotel Equatorial Shanghai \\ No.65, Yan An Road (West), Shanghai, 200040, China \\ 中国上海市延安西路65号上海国际贵都大饭店办公楼 405 单元 \\ Phone: +86-21-62489820 \\ Fax: +86-21-62489821
}


(C) 2012 The Author(s). Licensee IntechOpen. This is an open access article distributed under the terms of the Creative Commons Attribution 3.0 License, which permits unrestricted use, distribution, and reproduction in any medium, provided the original work is properly cited. 